\title{
MUNICÍPIOS SAUDÁVEIS: ASPECTOS CONCEITUAIS
}

\author{
Márcia Faria Westpha/*
}

\begin{abstract}
Resumo: Este texto discute a proposta de "Cidades Saudáveis", assumindo-a como uma resposta a mudanças que estão ocorrendo no contexto, tais como o crescimento da urbanização, mudança da concepção de Estado, a globalização, rapidez da comunicação, mudanças nos padrões epidemiológicos e outros. Analisa-a a partir de visões empiricas e técnicas sobre a proposta: uma forma de avaliação de municipios, um movimento mais amplo, uma filosofia, um projeto que procura experimentar uma nova forma de gerenciamento dos problemas das cidades. Referea a uma concepção ampla do processo saúde - doença e ao novo paradigma da Promoção de saúde. Apresenta e discute as condições necessárias dentre elas o compromisso politico das autoridades constituídas com metas, objetivos e estratégias relacionadas às necessidades da população que vive nas cidades. Para que as experiências sejam caracterizadas como tal, o planejamento estratégico, ações intersetoriais e principalmente o protagonismo da sociedade civil durante todo desenvolvimento do projeto são outros instrumentais disponiveis para os interessados em experimentá-la.
\end{abstract}

Palavras-chave: cidades saudáveis; conceituação; municipios saudáveis, saúde

* Professora Titular do Depto de Prática de Saúde Pública da Faculdade de Saúde Pública da USP. 
No começo da década de 70, em Toronto, no Canadá, surge o movimento denominado "Cidades Saudáveis" como uma das propostas estratégicas de trabalho em saúde, difundindose por várias cidades da Europa, que vêm tentando, através de novas formas de ação, criar melhores condições de vida para a população (STROZZI \& GIACOMINI, 1996).

Vários países da América Latina e alguns de seus Municípios, nos últimos anos tem se proposto a discutir e mesmo a por em prática esta forma altemativa de gerir a cidade. Os motivos que temos encontrado para isto são vários e tem a ver com a situação política econômica do país.

Neste final de século, o cenário mundial se configura como um movimento dinâmico de globalização, com marcante urbanização das populações nacionais, estabelecendo novas fronteiras econômicas, sociais e geográficas, provocando o surgimento de conflitos culturais, religiosos e humanos, com reflexos para a conjuntura nacional. Observa-se ao mesmo tempo um fortalecimento do poder local, de valorização das diferenças culturais entre outros aspectos, tornando este momento favorável para a discussão do acesso à vida, com qualidade, nas cidades.

As mudanças demográficas pelas quais o mundo todo está passando, especialmente os paises de terceiro mundo, no qual se incluem os países da América Latina, torna mais urgente a busca de uma nova estratégia para promover saúde, que dê conta dos problemas urbanos dos segmentos populacionais em sua amplitude O Índice de Urbanização cresceu vertiginosamente neste últimos cinqüenta anos, isto é depois da Segunda Guerra Mundial. No Brasil o índice percentual de população urbana que era de $26,35 \%$ na década de 50 , agora em 1991, já esta em 77,13\%. Mesmo a população agrícola vem se deslocando gradativamente para aárea urbana, provocando uma fenômeno interessante que é o aumento proporcionamente maior da população agrícola em relação à população rural. As regiões metropolitanas que eram três ou quatro agora estão aumentando em número, contribuindo para o aumento da população urbana (SANTOS, 1995).

Embora a cidade atraia pelas possibilidades que oferece às pessoas - culturais, educativas e de emprego - também cria muitos problemas, especialmente quando a aglomeração de população cresce a tal ponto, que os recursos tornam-se insuficientes para o atendimento das necessidades. As contradições urbanas se evidenciam, passando a agredir grande contingente populacional com problemas como violência, poluição do ar, solo e água provocando uma mudança nos padrões de morbidade e mortalidade que as condições das cidades, por outro lado, acabam criando. (NUNES, 1989) 
Aspectos políticos como a concepção de Estado Liberal mínimo, que embasa a ação de nossos governos, vem dissociando os Estados Latino americanos, esfacelados pela dívida externa, de suas obrigações sociais em relação à Saúde e Educação. 0 modelo de "privatização do público" já foi assumido por alguns países de nosso continente, nos colocando frente a frente com a necessidade de discutir as parcerias e a ética das mesmas (HABERMAS, 1984). O modelo de Saúde "Municípios Saudáveis" contrariamente, embora acene para necessidade de ampliação dos parceiros envolvidos no diagnóstico e solução dos problemas apresente-se também como uma estratégia de resistência, pois valoriza o homem e seu desenvolvimento individual e coletivo e não exime o Estado de sua responsabilidade social.

Um modelo econômico de desenvolvimento excludente, ancorado na estabilização monetária vem agravando a situação brasileira, a semelhança do que vem ocorrendo em outros paises da América Latina. $O$ aumento do desemprego e da pobreza decorrente deste mesmo modelo económico, eficiente em aumentar o produto interno bruto (PIB) por exemplo, tem provocado um aumento das desigualdades sociais e consequentemente uma deterioração das condições de saúde. Esta estratégia pressupõe um fortalecimento e uma reação da população a estas condições adversas.

O sedentarismo característico da vida dos indivíduos que vivem em uma sociedade tecnológica e industrial, a mudança do perfil demográfico referente ao aumento do contingente populacional das faixas etárias de mais idade, vem provocando mudança nos padrões de mortalidade, fazendo com que convivam a mortalidade e morbidade por doenças infecciosas com as crônico degenerativas. A busca de soluções ou a prevenção de novos fatores de risco, tem direcionado a solução das doenças para questões do estilo de vida, chamando atenção para o componente psicossocial do processo saúdedoença, agregando-o como causalidade, aos tradicionais componentes orgânicos e associando a sua redução a estratégias de Promoção de Saúde (PROMOÇÃO DA SAÚDE, 1996).

Como ainda pouco tem sido feito para enfrentar os determinantes socioeconômicos, políticos e culturais das doenças, e os investimento em saúde tem sido prioritariamente feito em assistência, os gastos em saúde não tem revertido em melhoria destas condiçôes. Várias pesquisas feitas no Canadá e Estados Unidos, comprovam esta afirmativa. Canadá que gasta menos com assistência que os Estados Unidos e investe mais com ações para a melhoria da qualidade de vida tem tido melhores resultados em saúde que o seu vizinho (HEALTH OECD, 1990). A proposta de Promoção da Saúde, estratégia mais utilizada no Canadá, sugere uma aceitação ou pelo menos uma experimentação deste caminho. 
Diante da expressão "Cidades Saudáveis", e da proposta a que ela se refere, a população, os técnicos e a mídia tem tido múltiplas interpretações, desde considerações avaliativas sobre as condiçöes do municipio em questão, para credenciá-lo como saudável, até outras que o entendem como qualificação de um projeto, que pretende ser uma proposta de transformação das condições de vida e saúde, em que o municipio se encontra. Em nivel internacional este termo vem sendo empregado para expressar uma filosofia de ação, baseada em uma concepção ampla de saúde que incorpora além dos aspectos biológicos que interferem no processo saúde doença, os determinantes sociais, econômicos e ambientais, ou melhor que ampliam o conceito de saúde, para além da consideração simples de saúde como "ausência de doença".

O então chamado movimento "Cidades Saudáveis", baseia-se em uma nova visão de Saúde, que incorpora à idéia de "assistência", de "cura", o aspecto de Promoção da Saúde.

Entende-se Promoção de Saúde como "um processo, através do qual a população se capacita e busca os meios para conseguir controlar os fatores que favorecem seu bem estar $e$ da comunidade ou que podem a estar pondo em risco, tornando-a vulnerável ao adoecimento e prejudicando sua qualidade de vida "(Otawa 1986). Nesta visão, saúde deixa de ser um objetivoa ser alcançado, tornando-se um recurso para o desenvolvimento da vida (PILON 1990, 1992; RUSSEL, 1995).

Os pré-requisitos básicos para a saúde deste ponto de vista são: a paz, a segurança politica e pessoal promovida através de políticas redistributivas, de apoio a família, de orientação da mídia e de segurança pública que farão a prevenção da violência nas ruas, a decorrente da repressão policial, a contida em certos relacionamentos homens - mulheres, nos relacionamentos pais - filhos e outros objetivos a serem atingidos; a posse da habitação, atendendo à necessidade básica de abrigo, adequada em termos de dimensões por habitante, condições de conforto térmico, presença de sanitários com ligações que permitam o destino adequado dos dejetos e outros; o acesso um sistema educacional atendendo à necessidade de informação, em condições que favoreçam a democratização da mesma, através de um processo ensino aprendizado eficiente, em que ocorram poucas repetências e evasões; disponibilização de alimentos através de políticas de produção e distribuição que garantam a chegada à mesa da população dos nutrientes em quantidade suficiente para o atendimento das necessidades biológicas, promoção do crescimento e desenvolvimento das crianças e adolescentes e reposição da força de trabalho; renda suficiente para o atendimento às necessidades básicas e pré-requisitos anteriores; recursos renováveis garantidos por uma politica agrária e industrial voltada para as necessidades da população e o mercado interno e não 
somente exportação e importação; ecossistema presenvado e manejado de forma sustentável para que as condições atmosféricas, ar e solo sejam saudáveis e não poluídas.

Estes pré-requisitos precisam ser garantidos por políticas educacionais, agrícolas, ambientais, de transporte urbano voltadas para o objetivo amplo de saúde, qualidade de vida e desenvolvimento humano orientado por valores democráticos de justiça e equidade (OPAS, 1996, STROZZI\& GIACOMINI, 1996).

A discriminação deste pré-requisitos, nesta perspectiva ampliada da saúde não permite mais, a restrição das ações relacionadas resolução das questões da qualidade de vida, ao setor saúde. Propõe a agregação das instituições em geral e dos atores sociais para, em conjunto, verificar como a sociedade está satisfazendo as necessidades básicas da população, a distribuição de bens e serviços, e tentando lidar com as carências decorrentes das iniquidade. Exige do Estado a garantia dos direitos humanos básicos.

Quando nos remetemos à Reforma Sanitária Brasileira eà Oitava Conferência Nacional de Saúde que foi um marco decisivo deste processo, vemos que a reflexão brasileira não aconteceu isoladamente, mas foi parte de um processo maior, uma necessidade internacionalmente reconhecida, de mudança de estratégia para atender aos objetivos de saúde da população mundial. (WESTPHAL, 1992)

A Primeira Conferência Internacional de Promoção de Saúde que ocorreu no Canadá, data de 1986, mesmo ano em que aconteceu nossa Oitava Conferência. Embora não existam muitos que façam a relação entre os dois eventos não há como separar suas perspectivas. Ambos defendiam a necessidade de se trabalhar Saúde através de seus determinantes principais; as condições de vida e trabalho da população. Declararam como principio a saúde como um direito e o passo seguinte foi a indicação de que este ficasse estabelecido com um preceito constitucional (WESTPHAL, 1992).

Entretanto, os esforços iniciais da discussão de uma estratégia intersetorial para dar conta da mediação saúde - determinantes socioeconômicos, políticos e culturais não foi muito longe. A discussão acabou restrita ao estabelecimento do Sistema Único de Saúde (SUS) e nele à prestação de Serviços de Saúde. Questões como a da poluição do ar, água e solo, mais recentemente vem sendo atribuída ao âmbito da Vigilância Sanitária das Secretarias de Saúde ou órgãos de Saneamento Básico, encarregados da aplicação de multa a instituições ou empresas infratoras de normas. Muito poucas vezes, a discussão deslocou-se para os setores educação, planejamento urbano, transporte e ampliando-se e adotando uma perspectiva mais preventiva. 
Os paises, na maioria do mundo desenvolvido, signatários da Carta de Otawa, ao contrário, vem todos este anos, experimentando com sucesso a estratégia de "Municipios Saudáveis". Esta que muitas vezes começa pelo setor saúde, depende basicamente do envolvimento dos outros setores da sociedade; dos atores sociais de governos, das empresas, das organizaçőes năo governamentais, das famílias e dos individuos em particular, que assumem a tarefa de consecuçăo de objetivos de melhoria da qualidade de vida.

As liçőes aprendidas destes paises pelo relato de experiências e muitas vezes pela produçăo cientifica que as embasa ou as tornar pública, indicam pressupostos que podem servir de guia para novas experiências. A intençăo de um município de entrar no movimento ou a participar das redes existentes pressupöe um compromisso das autoridades com a qualidade de vida e com as politicas. Depende de que estas assumam medidas mais adequadas para promover a vida.

Para que sejam adotadas politicas públicas saudáveis é necessário o adequado diagnóstico da situação, o mais amplo possível, obtido com a visăo dos técnicos "reorientada" pelos conhecimentos empíricos da populaçăo (DRUMMOND, M.\&. STODDART, 1995; EAKIN, 1996, MACDONALD, TONES \& VEEN, 1996).

A Cidade que resolver pertencer ao movimento de "Cidades Saudáveis", seu Prefeitoe seus vereadores, istoé o poder executivo e legislativo assume o dever de legislar adotarpoliticas públicas que resolvam os problemas apontados por estes diagnósticos, de forma integrada e intersetorial, para que as medidas sejam interrelacionadas e efetivas. Sua materializaçấ pressupôe um compromisso formal com a adoçăo de politicas públicas saudáveis que possam ajudar a lidar com as desigualdades e gradativamente ir diminuindo-as.

Pressupőe a existência de um plano de governo baseado na resoluçăo de problemas identificados, com base em indicadores de qualidade de vida. A proposta, o compromisso, écom as metas de um "Planejamento estratégico", estabelecido com as instituições representativas da sociedade como um todo, todas as classes sociais, todos os setores da sociedade e em parceria com os setores de governo.

O planejamento e gestão intersetorial, intersistêmica é outro pressuposto fundamental, que representa a união do setor saúde com os outros setores, pois sozinho não se pode fazer nada ou se faz muito pouco. Esta tarefa é difícil de ser viabilizada, mas possivel dentro de uma perspectiva processual e gradativa. Responde ao seguinte corolário: Saúde é algo que se cria socialmente e é produto e responsabilidade de todos num trabalho concreto e contínuo. 
A inserção e a relaçăo com o contexto geral do pais é outra premissa. O apoio dos outros niveis govemo é também fundamental, para que haja um reforço desta políticas e das medidas racionalmente definidas e para que não se assuma somente medidas que tenham efeito imediato e eleitoreiro (OFFE, 1984).

Porém, estas indicações não fazem sentido sem o Protagonismo da Sociedade Civil através da participação da população, através de seus grupos organizados, que são os que vivem e sentem os problemas no seu dia a dia de trabalho, e de convivência nas comunidades. Muitas vezes as soluções racionalmente pensadas, não são adequadas à realidade da população. Se a discussão for aberta, as soluções serão mais reais e efetivas e a sociedade um ator da sua própria mudança.

A proposta de "Municipios Saudáveis" recomenda a participação da população em Conselhos Municipais centrais, distritais e locais que possibilitem a incorporação das suas informaçőes e necessidades aos diagnósticos racionais, que permitam o fortalecimento do poder popular e a sua participação nas decisões construindo junto com os técnicos, uma sociedade mais justa e igualitária.

Nestes, as-sociedades amigos de bairros, as organizações não governamentais, os sindicatos de trabalhadores, as associaçōes setoriais, a organizações não govemamentais poderão dar uma grande contribuição aos técnicos que poderão apreender o conhecimento empírico destes grupos, ao mesmo tempo que a população poderá compartilhar os avanços do conhecimento científico, visualizando aspectos técnicos dos problemas em questão (TONES, 1994).

O último aspecto da estratégia é a reorientação dos serviços de saúde para dar conta da saúde nesta visão ampla, promovendo o acesso eqüitativo aos serviços e programas, incrementando atividades promocionais e preventivas. Este é um problema sério e complexo que faz parte desta discussão, mas que optamos por não aprofundar aqui.

As avaliações tem reforçado aos que atuam na área da Promoção de Saúde, que "Município Saudável" é uma estratégia a longo prazo, mas efetiva. A racionalização dos recursos, e a escolha adequada das ações, com um trabalho intersetorial tem muito maior probalidade de ser bem sucedida. Muitos problemas relacionados à poluição do ar, recuperação do meio ambiente, transporte urbano, tem sido objeto de ações na perspectiva de "Municipios Saudáveis" e tem possibilitado resultados relevantes. 
Se o prefeito da cidade de Săo Paulo, resolvesse através da Organização Panamericana de Saúde, se inserir no movimento "Municípios Saudáveis", deveria se dispor a mudar gradativamente sua forma de administrar, porque esta proposta nada mais é do que uma nova forma de gestão municipal. A experiência canadense, européia, de alguns países da América Latina e agora em algumas cidades do Paraná e estado de São Paulo tem demonstrado que a proposta de Municípios Saudáveis é viável, eficiente, mas que só é viável políticamente, com dirigentes estatais comprometidos com a causa social, com a qualidade de vida da populaçãoe tecnicamente preparados (STROZZI \& GIACOMINI, 1996).

Para metrópoles como São Paulo, programas com ações de "larga escala" e de desenvolvimento local são necessárias. A cidade de Tóquio, no Japão, que está longe de ser saudável, já está se preparando para enfrentar os problemas do terceiro milênio com armas mais eficientes. A estratégia de "Municipios Saudáveis" já está em curso na região metropolitana da capital daquele país. A questăo da poluiçăo ainda não está resolvida, nem mesmo a do transporte coletivo, mas o processo já está iniciado e os problemas aos poucos se resolvendo, com a participação da sociedade civil (SANDERSON, 1996).

Esperamos ter sintetizado as contribuições da literatura internacional apresentando as conceituações básicas de uma nova perspectiva, um novo olhar, uma nova alternativa de gestão que deve ser incorporada às existentes, para a resolução dos problemas da cidade. A busca da racionalização de recursos através da abordagem de projetos a partir de uma perspectiva intersetorial, envolvendo diferentes órgãos de governo e setores da sociedade local, tem sido uma alternativa dificil, porem muito utilizada por alguns administradores mais ousadose comprometidos com o desenvolvimento integral e sustentado.

\section{REFERÊNCIAS BIBLIOGRÁFICAS}

DRUMMOND, M \& STODDART, G. Assessment of health producing measures across different sectors. Health Policy, 33:219-31, 1995.

EAKIN, J. et al. Toward a critical social science perspective on health promotion research. Health Prom. Int., 11: 157-65, 1996.

HABERMAS, J. Mudanças estruturais na esfera pública. Rio de Janeiro, Tempo Brasileiro, 1984. p. 42-109.

HARRIS POLL \& AECD DATA - Health Affair, 1990. 
MACDONALD, G.et al. Evidence for success in health Promotion: suggestions for improvement. Health Educ. Res., 11:367-76, 1996.

NUNES, E. Carências urbanas, reivindicações sociais e valores democráticos. Lua Nova (17): 67-92, 1989.

OFFE, C. Dominação de classe e sistema político sobre seletividade das instituições politicas In: OFFE, C. Problemas estruturais do Estado capitalista. Rio de Janeiro, Tempo Brasileiro, 1984. p: 140-77.

ORGANIZACIÓN PANAMERICANA DE LA SALUD Promotion de la salud: una ontologia Washington, D.C., 1996.

PILON, A.F. Health for all by the year 2.000 - cultural handicaps and possible solutions. Int. Q. Community Health Educ., 11:79-83, 1990/91.

PILON, A.F. Qualidade de vida e formas de relacionamento homem-mundo. Rev. Bras. Saúde Esc., 2(3/4):117-25, 1992.

PROMOÇÃO DA SAÚDE: Carta de Otawa, Declaração de Adelaide, Sundsval e Santa Fé de Bogotá. Tradução: Luis Eduardo Fonseca. Brasilia, Ministério da Saúde, 1996.

RUSSEL, A.J. What is health? People talking. The joumal , 43-7: 1995

SANDERSON, $C$ et al. Effect and stage models in community intervention programs; and the development of the model for management of intervention programme preparation. Health Prom. Int., 11:143-55, 1996.

SANTOS, M. A urbanização brasileira. $3^{\text {a }}$ ed. São Paulo, Hucitec, 1995.

SPRINGETT, J etal. Toward a framework for evaluation in health promotion: methodology, principles and practice. The Joumal, 8: 61-5, 1995.

STROZZI, J.B. \& GIACOMINI, M. Municipio saudável. Divulgação Saúde em Debate, 16:30-5, 1996.

TONES, K. Health promotion, empowermentand action competence. In: Jensen, B. B. \& Schnack, 
K. Action and action competence. R. Dan. Sch. Educ. Stud. Studies in educational Theory and Curriculum 12:, 163 - 183, 1994.

WESTPHAL, M.F. Participação popular e políticas municipais de saúde: o caso de Cotia e Vargem Grande Paulista. São Paulo, 1992. [Tese de Livre-docéncia da FSP/USP]

\begin{abstract}
Summary: This text discusses the proposal of "Healthy Cities" assuming it as an answer to changes that are happening in the context, such as the growth of the urbanization, change of the conception of State, the globalization, speed of the communication, changes in the epidemic pattems and others. The paper analyzes it departing from empiric and technical visions of the proposal: a form of evaluation of municipal districts, a wider social movement, a philosophy or a project that tries a new form of management of the problems of the cities. The proposal is structured within a wide framework of the health - disease process and a new paradigm of Health Promotion. The text presents and discusses the necessary conditions to the political commitment of the authorities to goals, objectives and strategies related to the needs of the population of the cities. Other avaliable tools for those interested in trying out the proposal are the strategic planning, intersectorial action and mainly the protagonism of civil society during the whole development of the project.
\end{abstract}

Key words: healthy cities; conceptualization; health 